\title{
O Caminho se Faz ao Caminhar: Novas Perspectivas da Educação Médica no Contexto da Pandemia
}

\author{
The Path Is Made by Walking it: New Perspectives for Medical Education in the Pandemic Context
}

\author{
Laíse Carla da Costa Felisberto' ${ }^{\mathbb{D}}$, Patricia Estela Giovannini' ${ }^{\mathbb{D}}$, Isabelle Cantídio Fernandes Diógenes'
} Lucas Pontes Nunes Carlos' ${ }^{\mathbb{D}}$, Lindercy Francisco Tomé de Souza Lins' $\mathbb{1 D}^{\mathbb{C}}$

\begin{abstract}
RESUMO
Introdução: Este relato aborda os aspectos relacionados à experiência vivenciada durante a pandemia da Covid-19, na vigência da suspensão das atividades presenciais da Universidade do Estado do Rio Grande do Norte (UERN), e apresenta a estratégia desenvolvida por meios digitais para mitigar os impactos no processo formativo de futuros médicos e na atenção à saúde de mulheres e adolescentes. Participaram três professoras do Departamento de Ciências Biomédicas (DCB-UERN), 31 estudantes do curso de Medicina, 12 residentes do Programa de Residência Médica em Ginecologia e Obstetrícia (PRMGO) da UERN/Prefeitura Municipal de Mossoró (PMM), dois técnicos e 150 pacientes, em espaços virtuais e nos cenários de práticas do PRMGO da UERN/PMM, em ambulatórios de ginecologia e obstetrícia (GO) da FACS/UERN e no Programa de Extensão Pró-Mulher.
\end{abstract}

Relato de Experiência: Realizaram-se 18 webinários multiprofissionais, além da utilização de um aplicativo para acompanhamento no prénatal, redes sociais como ferramentas de promoção da saúde e desenvolvimento de pesquisa e um instrumento de avaliação da qualidade da informação em saúde.

Discussão: Ações de apoio ao estudante e o estímulo ao desenvolvimento docente contribuem para a redução dos impactos da pandemia, nas dimensões da educação e da atenção à saúde. O envolvimento de estudantes na produção de materiais educativos e a realização de palestras e sessões demonstrativas por meios remotos podem promover a aprendizagem e o desenvolvimento de competências médicas. Entretanto, o uso das tecnologias digitais na educação médica e na atenção à saúde implica enorme responsabilidade ética, social e política perante a salvaguarda dos direitos humanos, devendo ser assegurada a utilização adequada e segura das tecnologias.

Conclusão: Em cenários desafiadores no interior do Rio Grande do Norte, na Região Nordeste, é possível promover a aprendizagem significativa e contribuir para o desenvolvimento de competências médicas mediante a inclusão digital genuína, com ações integradoras e interdisciplinares, cujos benefícios poderão ser ampliados por políticas afirmativas que contemplem as características e os indicadores regionais, de modo a diminuir as assimetrias.

Palavras-chave: Educação Médica; Inclusão Digital Genuína; Telemedicina.

\section{ABSTRACT}

Introduction: This study reports on an experience during the COVID-19 pandemic, where in view of the suspension of face-to-face activities at the Universidade do Estado do Rio Grande do Norte (UERN), a strategy was developed using digital resources, aimed at mitigating the negative impacts on the training of future doctors and health care of women and adolescents. The work involved the participation of three professors from the Department of Biomedical Sciences (DCB - UERN), 31 medical students, 12 residents of the Medical Residency Program in Gynecology and Obstetrics (PRMGO) at UERN / Prefeitura Municipal de Mossoró (PMM), two technicians and 150 patients, in virtual spaces and in the practice scenarios of the PRMGO, the Gynecology and Obstetrics (GO) Outpatient Clinic at FACS/UERN, and the Pro-Women Outreach Program.

Experience report: 18 multi-disciplinary webinars were held; an application for monitoring prenatal care was used, as well as social networks as tools for promoting health, research development and an instrument for assessing the quality of the health information.

Discussion: Actions to support students and encourage teacher development contribute to reducing the impacts of the pandemic on aspects of education and health care. Student engagement, the development of educational products, and holding remote lectures and demonstration sessions can promote learning and the development of medical skills, but, in to guarantee the safeguarding of human rights, the use of digital technologies in medical education and health care implies great ethical, social and political responsibility, and so the appropriate and safe use of technologies must be ensured.

Conclusion: In challenging scenarios in the interior of Rio Grande do Norte, Northeast Brazil, it was possible to promote meaningful learning and contribute to the development of medical skills through genuine digital inclusion, based on integrative, interdisciplinary actions, the benefits of which can be broadened by affirmative policies that address regional characteristics and indicators, and reduce asymmetries.

Keywords: Education Medical; Genuine Digital Inclusion; Telemedicine.

'Universidade do Estado do Rio Grande do Norte, Mossoró, Rio Grande do Norte, Brasil.

Correspondência

Laíse Carla da Costa Felisberto.

Rua Lourival Caetano Ferreira, 498, Alto do Sumaré, Mossoró, RN, Brasil. CEP: 59633-710.

E-mail: laisekarla@hotmail.com

Recebido em 11/08/20; Aceito em 13/09/20 


\section{INTRODUÇÃO}

Em tempos da coronavirus disease 2019 (Covid-19), alterações e incertezas quanto à formação e ao provimento de médicos acompanharam essa pandemia, desde o início, trazendo grandes desafios a escolas e estudantes, e uma séria ameaça à assistência médica, para pessoas e comunidades, mundialmente.

No Rio Grande do Norte, a primeira determinação para suspender as atividades presenciais em instituições públicas de ensino superior (Ipes) entrou em vigor em 15 de março de 2020, por meio da Portaria n³ 346/2020-GP/Fuern', estabelecendo orientações, no âmbito da Universidade do Estado do Rio Grande do Norte (UERN), quanto às medidas preventivas no enfrentamento da grave situação de saúde pública de importância internacional.

Entre as primeiras ações, após a suspensão do período letivo por tempo indeterminado, destacam-se um inquérito institucional ${ }^{2}$, com os objetivos de conhecer o perfil digital e promover acesso do corpo discente a internet e equipamentos, e a primeira colação de grau on-line da UERN, na qual foram formados 28 médicos. Esse tipo de colação de grau alcançou repercussão nacional não apenas por causa da modalidade, considerada inédita em abril de 2020, mas também pelo fato de os formandos terem completado 93,39\% do internato, o que suscitou controvérsias relacionadas à antecipação da formatura. Entretanto, ante a mudança no quadro epidemiológico, foi considerada uma medida governamental para reforçar o combate ao novo coronavírus 3 .

Destaca-se ainda a manutenção dos programas de pósgraduação na UERN, como o Programa de Residência Médica em Ginecologia e Obstetrícia (PRMGO) da UERN/Prefeitura Municipal de Mossoró (PMM). Além disso, mantiveram-se os serviços dos ambulatórios de ginecologia e obstetrícia (GO) da Faculdade de Ciências da Saúde (FACS/UERN) e os convênios com o Sistema Único de Saúde (SUS), cujo funcionamento no período pandêmico contempla a atenção a adolescentes e mulheres em condições ou contextos de vulnerabilidades, conforme as recomendações da Federação Brasileira das Associações de Ginecologia e Obstetrícia (FEBRASGO) 4 .

Nesses cenários, a manutenção da residência no período pandêmico favoreceu a definição de alternativas diante dos desafios que surgiram nesse contexto, tanto no campo da atenção quanto no da educação médica. Assim, a residência teve um papel relevante, pois contribuiu para a reorganização do serviço, colaborou na promoção, prevenção, assistência e recuperação da saúde feminina, e promoveu oportunidades de aprendizagem de forma ímpar, beneficiando tanto os residentes quanto os estudantes de graduação, conforme será descrito no presente relato.

No campo da atenção, apesar de as recomendações vigentes $^{4}$ contemplarem $\mathrm{o}$ atendimento em determinadas condições e nos casos de vulnerabilidades, a restrição do acompanhamento rotineiro colocava o desafio de estabelecer canais de comunicação alternativos que, para além do mero contato, possibilitassem a intercomunicação entre as adolescentes e mulheres, seus familiares, a comunidade e a equipe médica, observando os princípios da humanização e preservando o vínculo, no intuito de estimular a adesão às medidas sanitárias para prevenção da Covid-19 e às orientações, bem como a disseminação de informações confiáveis.

Por sua vez, no contexto do curso de Medicina da UERN, na dimensão da educação, os desafios envolviam aspectos institucionais, dos docentes e dos estudantes. Quanto aos primeiros, um ponto prioritário era implementar um plano de ações para avaliar a evolução da pandemia no estado e elaborar uma proposta de retomada das atividades em condições de segurança, considerando o incentivo ao diagnóstico e a resolução de fragilidades. Nessa direção, em maio de 2020, foi reconstituída a Comissão Especial de Consulta (CEC) para auxiliar o reitor nas decisões para a retomada das atividades ao término do isolamento social5.

Ademais, considera-se que, na conjuntura configurada a partir da pandemia, a ampliação da capacidade dos docentes, para lidar com essa situação atípica e suas consequências, está intimamente relacionada ao desenvolvimento docente. No entanto, diversos fatores podem interferir na sua disponibilidadee na adesão dos docentes, como questões de carga horária, vínculo institucional e incentivo limitado por restrições orçamentárias, que, infelizmente, é bastante comum, principalmente em Ipes. Nesse ponto, vale destacar a importância das iniciativas apresentadas pela Pró-Reitoria de Gestão de Pessoas (PROGEP/ UERN), por meio do Programa CapaciTEC ${ }^{6}$, criado em maio de 2020, cujas ações contemplam de forma diferenciada os distintos grupos da comunidade acadêmica.

Em relação aos estudantes, características dos perfis demográfico e socioeconômico dos discentes do curso de Medicina da UERN e da composição do corpo discente sugerem que, no contexto da pandemia, o estímulo à permanência no curso e as consequências potenciais para a economia, representadas pelo aumento dos riscos de achatamento da renda familiar e do surgimento de situações que tornem imperativo uma busca de alternativas, por meio de inserção no mercado de trabalho, trazem grandes desafios a serem superados pelos alunos, o que pode ser mais difícil para os que percorrem longas distâncias, desde a cidade de origem até o câmpus. Tudo isso realça a importância do olhar atento e sensível dos professores e do apoio institucional, por meio das ações de assistência ao estudante, estabelecidas pela PróReitoria de Assuntos Estudantis (PRAE/UERN). 
O perfil dos estudantes do curso de Medicina da UERN foi assunto de um estudo realizado por Cardoso Filho, Magalhães et al. ${ }^{7}$ o qual mostrou que $61,1 \%$ dos alunos eram provenientes da rede pública de ensino, enquanto $87,5 \%$ eram sustentados pela família, 83,3\% não exerciam atividade acadêmica remunerada e $93 \%$ não participavam de nenhum programa de assistência estudantil. Quanto à renda, 20,5\% declararam que tinham uma renda familiar de até $\mathrm{R} \$ 2.565,00$. Por sua vez, das 58 vagas iniciais preenchidas para o ano de 2020, 44\% (26) foram de alunos não cotistas com bônus regional residentes no Rio Grande do Norte, 31\% (18) corresponderam a alunos autodeclarados pretos, pardos e indígenas (PPI), $17 \%$ (dez) referiam-se a egressos de escola pública não PPI e 7\% (quatro) foram de pessoas com deficiência (PCD). Tal distribuição está alinhada com as mudanças instituídas pela Lei Estadual $n^{\circ} 10.480 / 2019^{8}$, a qual destina $50 \%$ das vagas iniciais aos alunos que tenham cursado integralmente os ensinos fundamental e médio em escolas públicas, estabelecendo que, dessa percentagem, $58 \%$ são para candidatos autodeclarados PPI e 42\% são preenchidas por candidatos não PPI egressos de escola pública. A lei manteve cota de $5 \%$ destinada às $P C D$ e criou bonificação de $10 \%$ na nota final do Exame Nacional de Ensino Médio para o candidato que tenha cursado integralmente os ensinos fundamental e médio no Rio Grande do Norte.

No tocante ao acesso digital, $89,9 \%$ dos estudantes de Medicina da UERN utilizavam a internet como principal fonte de informação e 58,3\% possuíam computador ligado à internet, em dados de $2013^{7}$. Já na pesquisa institucional, realizada em março de 2020, o curso de Medicina ocupou o quinto lugar entre 37 cursos, com 170 respondentes $^{2}$, o que equivale à metade do corpo discente, aproximadamente. No entanto, levando em conta que uma parcela expressiva do corpo discente é proveniente de estados e regiões distantes e que a coleta dos dados aconteceu após a suspensão das atividades curriculares, é provável que, por dificuldades de acesso ou bem, por outros motivos, um número considerável dos estudantes desse grupo não tenha acessado o inquérito. Contudo, as fragilidades evidenciadas no estudo ${ }^{2}$ representavam indicativo para ações de apoio à inclusão digital, em curto prazo, cujo encaminhamento se deu por meio de edital para concessão de auxílio?.

No entanto, apesar do conjunto de medidas instituídas na tentativa de reduzir os impactos da pandemia sobre a educação superior no âmbito do estado e sobre a sociedade como um todo, houve um panorama de sucessivas avaliações negativas que protelaram o retorno às atividades presenciais. Esse adiamento provocou impacto emocional, diante do súbito eclipse de trilhas e veredas para a formação médica, uma consequência imediata do avanço da pandemia, das perdas incalculáveis, cujo dimensionamento no estado, em termos de acumulados casos e de óbitos confirmados por Covid-19, no período de 28 de março a 6 de agosto de 2020, foi de 54.106 e 1.954 , respectivamente. Das vítimas fatais, $1 \%$ era composto de profissionais de saúde que atuavam na linha de frente ${ }^{10}$. Além disso, havia as incertezas sobre o porvir, o que revelava o aspecto desalentador dessa difícil situação.

$\mathrm{Na}$ ausência de trilhas conhecidas, a iniciativa descrita no presente relato possibilitou a (re)construção de um caminho comum, trilhado passo a passo, no intuito de gerir impactos decorrentes da pandemia causada pela Covid-19, no processo formativo de futuros médicos e na saúde e vida de adolescentes e mulheres.

\section{RELATO DE EXPERIÊNCIA}

Trata-se do desenvolvimento e da implementação de uma estratégia cujos objetivos eram estimulara permanência de estudantes de Medicina no curso, no período de suspensão das atividades curriculares na UERN, e proporcionar oportunidades de aprendizado, por meios remotos, com captação de créditos em atividades complementares, mediante a participação em ações institucionalizadas, de pesquisa e extensão.

Para tanto, foram desenvolvidas quatro abordagens: 1. atividades de ensino-aprendizagem por meio de webinários; 2. ações de extensão por meio de redes sociais; 3 . utilização de um aplicativo para o monitoramento de informações no pré-natal; 4. desenvolvimento de pesquisa utilizando ferramentas digitais.

Participam três professoras do Departamento de Ciências Biomédicas (DCB/UERN), 31 estudantes do curso de Medicina da FACS, 12 residentes do PRMGO da UERN/PMM, dois técnicos e 150 pacientes, nos cenários de práticas do PRMGO da UERN/PMM, dos ambulatórios de GO da FACS/ UERN e em espaços virtuais. O percurso começou em abril de 2020 com a capacitação da equipe, mediante participação em ações institucionais ${ }^{6}$ e eventos realizados pela Associação Brasileira de Educação Médica (Abem) ${ }^{11}$ e Afya Educacional ${ }^{12}$.

O planejamento foi realizado em reuniões virtuais, desenvolvendo uma estratégia cuja configuração possibilita a integração entre estudantes do curso de Medicina, residentes, docentes, técnicos e pacientes, e permite realizar atividades acadêmicas com integralização de créditos complementares, bem como atividades de ensino-aprendizagem extracurriculares, de forma segura e por meios digitais.

Na dimensão da extensão, as atividades são realizadas no âmbito do Programa Pró-Mulher, o qual vincula sete projetos de continuidade, ativos desde 2013, seis deles no campo da saúde feminina, articulados às disciplinas de $\mathrm{GO}$ e ao internato do curso de Medicina, às ações dos ambulatórios de GO da FACS, do PRMGO da UERN/PMM, além do Projeto Educação, Saúde e Comunidade, integrado às disciplinas 
Microbiologia Médica e Imunologia, do terceiro período do curso de Medicina. Cursos e eventos realizados pelo programa realçam a atenção integral e a qualificação profissional em áreas e regiões prioritárias para o SUS e estimulam a produção acadêmica. Como exemplos, citam-se o ciclo de capacitações de profissionais em serviços de saúde de Mossoró (RN) e região para implementação da normativa de atendimento a vítimas de violência sexual ${ }^{13}$, a construção do projeto de implantação de um centro de referência integrado para atendimento a crianças, adolescentes e mulheres em situação de violência sexual ${ }^{14}$, em parceria com o Ministério Público, a participação na equipe do primeiro trabalho de conclusão de residência (TCR) do PRMGO da UERN/PMM ${ }^{15}$ e uma dissertação que abordou o atendimento a vítimas de violência sexual em cenários da atenção primária ${ }^{16}$, aprovada recentemente.

As abordagens foram implementadas da seguinte forma:

- Webinários multiprofissionais do PRMGO da UERN/ PMM: Desde abril de 2020 até o presente, foram realizadas 18 sessões, com as contribuições de docentes, preceptores, residentes e profissionais convidados, provenientes de diversos setores e áreas. O público-alvo são estudantes, docentes e profissionais com interesse na temática saúde da mulher. O envio do link de acesso é realizado mediante inscrição prévia. A divulgação é feita por meio do PRMGO da UERN/PMM, da FACS e das redes sociais. Estudantes do curso de Medicina da UERN participam nas atividades, no registro e na divulgação. Entre os temas abordados, estão: Covid-19 e gestação, puberdade normal, tardia e precoce, manejo clínico e conduta obstétrica em gestantes cardiopatas, papilomavírus humano (human papillomavirus-HPV), câncer de colo uterino, doença trofoblástica gestacional, endometriose e diabetes gestacional. Consideraram-se diretrizes, aspectos éticos, condutas, procedimentos, planos terapêuticos e a continuidade do cuidado, no contexto da rede de atenção, contando com a participação de quase 20 pessoas semanalmente. As atividades são avaliadas por docentes do PRMGO da UERN/PMM e pelos participantes, mediante devolutivas digitais.

- Redes sociais como ferramenta de educação e informação em saúde: Trata-se de atividades e produtos disponibilizados pela equipe, por meio da página do Programa Pró-Mulher no Instagram", criada em julho de 2020. O público-alvo são adolescentes, mulheres e seus familiares. Os assuntos são propostos por pacientes e pessoas da comunidade, diretamente, ou por residentes e professoras, que identificam interesses e necessidades durante os atendimentos. Com apoio em estudos e orientações, os estudantes produzem as peças, as quais são socializadas com a equipe por meio de aplicativo de mensagens, e os produtos finais são postados no Instagram ${ }^{17}$. No primeiro mês de existência da página, os discentes desenvolveram diversos produtos: um panfleto informativo sobre violência doméstica ${ }^{18}$, outro com recomendações para gestantes, puérperas e matrizes em tempos de Covid-19 ${ }^{19}$, infográficos sobre pré-natal ${ }^{17}$, calendário vacinal da gestante ${ }^{20}$, e sobre gravidez e pré-natal em adolescentes ${ }^{21}$, além de um fôlder sobre HPV ${ }^{22}$. A página e os materiais são avaliados pelos membros da equipe, quanto a características técnico-científicas, lexicográficas e competências trabalhadas, e pelo público, quanto à utilidade e compreensibilidade.

- Ampliação da utilização e funcionalidades do Aplicativo PreNeonatal23: Produto de parceria entre o Projeto Mãe Primavera do DCB e o Departamento de Informática (Dinf) da UERN. A aplicação foi desenvolvida em $2018^{24}$ e avaliada pela equipe médica do ambulatório de gravidez na adolescência da FACS, a qual orienta as gestantes a efetuar o download gratuitamente, via Google Play $^{23}$, e adicionar informações que são utilizadas no acompanhamento. Recentemente, a aplicação recebeu atualizações que estão sendo testadas.

- Pesquisa sobre características da informação digital em saúde e construção de um instrumento de avaliação da qualidade da informação em saúde: $\mathrm{O}$ encaminhamento foi aprovado em plenária do DCB/ UERN em julho de 2020, mediante projeto de pesquisa com a utilização de plataformas digitais, recebido pela Pró-Reitoria de Pesquisa e Pós-Graduação (Propeg/ UERN) e encaminhado para avaliação ad hoc.

\section{DISCUSSÃO}

Dentre as muitas lições aprendidas na experiência vivenciada, a primeira foi a importância do não negacionismo, especialmente em questões de saúde pública de interesse internacional. Considera-se que a celeridade na tomada de decisão institucional, suspendendo as atividades presenciais, dentro de um intervalo menor do que 48 horas após a caracterização pela Organização Mundial da Saúde (OMS) da Covid-19 como pandemia ${ }^{25}$, provavelmente contribuiu para a 
preservação de milhares de vidas na comunidade uerniana e no estado, uma vez que a instituição está presente em todas as regiões. Apesar do infortúnio de ocorrências de casos confirmados e de óbitos causados pelo vírus, a probabilidade de uma grande parcela da comunidade e pessoas próximas serem atingidas seria muito maior, a depender da demora nessa decisão. A memória é o alicerce para a construção de um futuro melhor e, diante dessa grave emergência epidemiológica, um gesto de respeito e homenagem às vítimas da doença e aos seus familiares. Diferentemente disso, o negacionismo, conforme alerta Caponi ${ }^{26}$, pode levar a uma situação de descontrole da pandemia, à aceitação de intervenções sem validação científica e ao desrespeito dos direitos dos grupos vulneráveis.

O segundo aprendizado veio por meio do desenvolvimento docente, o qual até o início da pandemia, apesar de ser considerado, nem sempre era devidamente priorizado, porém, no atual cenário, ganhou novos significados, como elemento transformador, entre avançar e um provável ônus de difícil dimensionamento. Vale frisar que a disponibilidade de apoio pode agir como um meio motivador e ampliar o acesso de docentes ao desenvolvimento profissional, ideia que parece ser reforçada pela expressiva participação de docentes do ensino superior na área de saúde, em eventos de qualidade nesse campo fundamental, cuja oferta de forma gratuita tem sido notável nos últimos meses. Ações como essas devem perdurar e ser disseminadas, reafirmando o papel social de instituições, órgãos públicos, associações, corporações e demais atores sociais no desenvolvimento docente, agregando valiosos subsídios para gerir os impactos decorrentes da pandemia.

Ao mesmo tempo, importa redobrar os esforços nas ações de apoio ao estudante, grupo particularmente vulnerável diante da suspensão das atividades curriculares na universidade. Nesse intuito, além do processo seletivo para concessão do auxílio inclusão digital ${ }^{9}$, a Prae/Uern ampliou o rol de programas de assistência estudantil ${ }^{27}$, e foi criado o projeto Doação Digital, o qual incentiva a doação de equipamentos de informática aos estudantes menos favorecidos da Uern ${ }^{28}$.

A experiência relatada põe a ênfase no trabalho em equipes e redes, ampliando colaborações e parcerias, valendose de forças e elementos disponíveis, (re)significados, sob as lentes da adaptação organizacional e operacional, de forma integrada, alinhada com disposições vigentes. Dentro de um contexto atípico e de uma situação difícil, de isolamento social, com atividades curriculares suspensas em vários cursos de graduação em Medicina, entre eles, o da UERN, destaca-se o aceno para a possibilidade da retomada das atividades por meios remotos, levando, consequentemente, ao debate sobre uma problemática ainda muito pouco explorada, a qual inclui questões éticas, pedagógicas, logísticas, culturais e de inclusão. Nesse cenário, a motivação para abraçar a iniciativa narrada teve o intuito de expandir a capacidade de resposta ante a difícil situação vigente, mobilizando potencialidades e mecanismos internos, no sentido de criar possibilidades, manifestando, no campo real, o conceito definidor de resiliência ${ }^{29}$.

O envolvimento de estudantes de Medicina em atividades como as que foram descritas, produzindo materiais de educação e informação em saúde e participando em palestras e sessões demonstrativas por meios remotos, aproxima-se das possibilidades consideradas por docentes das escolas da Filadélfia, nos Estados Unidos ${ }^{30}$, e de Singapura, na China ${ }^{31}$, os quais recomendam a utilização de abordagens e ferramentas digitais como as que foram aplicadas nessa estratégia, pois podem ser úteis para promover a aprendizagem e o desenvolvimento de competências médicas, especialmente no atual contexto de pandemia.

A utilização de uma rede social, que, na vigência das medidas de isolamento, oportunizou a realização de ações de extensão, foi o início de uma construção de pontes interativas, cujas interligações contribuem para o fortalecimento do vínculo e da comunicação que facilita a continuidade do cuidado. Iniciativas como essa crescem pelo Brasil e, por meio de ações, constroem novos sentidos às práticas educativas, como na experiência divulgada por um projeto da Faculdade de Medicina da Universidade Federal de Minas Gerais (UFMG) ${ }^{32}$. Nessa mesma direção, Ceccon e Schneider ${ }^{33}$ propõem um conjunto de estratégias para o enfrentamento da pandemia, com destaque para as tecnologias leves e a educação em saúde, considerando que

[...] neste caso, não se trata apenas de atos de transmissão de conhecimento sobre o Coronavírus, mas um processo ético, estético, político e pedagógico que requer o desenvolvimento do pensamento crítico e reflexivo, permitindo desvelar a realidade e implementar ações inovadoras, como é o caso do isolamento social.

Por sua vez, o desenvolvimento de estudos e instrumentos que contribuam para o processo de comunicação em saúde permite trabalhar um conjunto relevante de competências médicas e habilidades, nas três áreas propostas pelas Diretrizes Curriculares Nacionais ${ }^{34}$ (DCN), abordando uma pauta desafiadora, diante do prejuízo potencial, configurado pela disseminação de notícias falsas por meios digitais em plena pandemia, e as demandas existentes nesse terreno.

Essa discussão não poderia deixar de considerar aspectos éticos e bioéticos dos novos horizontes da atenção e da educação das profissões em saúde que se descortinam no contexto da grave pandemia. O item nove da "Declaração sobre a COVID-19: considerações éticas sob perspectiva global”, 
do Comitê de Bioética Internacional (CIB) da Organização das Nações Unidas para a Educação, a Ciência e a Saúde (Unesco) e da Comissão Mundial para a Ética do Conhecimento Científico e Tecnológico (Comest) da Unesco ${ }^{35}$, reconhece o importante papel que as tecnologias digitais, as redes sociais e a inteligência artificial (IA) podem desempenhar no enfrentamento da pandemia, implicando uma enorme responsabilidade ética, social e política com a salvaguarda dos direitos humanos, devendo ser assegurada a utilização adequada das tecnologias. Nessa perspectiva, a construção de um código de ética global para a pesquisa em $I^{36}$ é um dos principais desafios postos à comunidade universal no século XXI para superar o descompasso entre os avanços no campo da ética e o desenvolvimento tecnológico. E enquanto o futuro avança a passos largos, Dravet e Castro ${ }^{37}$ acenam com propostas para um novo paradigma na educação superior. Com os aportes da teoria da complexidade, apontam para um possível caminho a ser trilhado, buscando o equilíbrio das relações entre a hegemonia dos meios digitais e os conhecimentos necessários a uma formação integral do ser humano.

\section{CONCLUSÃO}

Foi descrita uma experiência de enfrentamento diante dos impactos decorrentes da pandemia por Covid-19, no processo de formação de futuros médicos, na atenção à saúde de mulheres e adolescentes e na continuidade do cuidado. A experiência mostrou que a presença de limitações materiais e tecnológicas e de elementos de vulnerabilidade não necessariamente se traduz em barreiras à educação médica de qualidade e ao desenvolvimento de competências médicas. Mediante ações integradas entre ensino, serviço e comunidade, graduação e residência, com apoio no tripé acadêmico formado pelo ensino, pesquisa e extensão, é possível dar respostas positivas a uma situação difícil, em cenários desafiadores, no interior do Rio Grande do Norte, na Região Nordeste do Brasil, e avançar na direção de uma inclusão digital genuína, que, para além do mero uso de tecnologias digitais, possibilite experiências de aprendizagem significativa.

A integração é um elemento fortalecedor e um objetivo a ser conquistado para muitas escolas médicas que, como a FACS/UERN, vivenciam a transição entre o currículo misto e a construção de um currículo integrado, cuja implementação provavelmente facilitará o envolvimento de um elevado número de participantes em ações acadêmicas como as que foram descritas, criando oportunidades e situações de ensinoaprendizagem e contribuindo para a creditação de carga horária exigida no projeto pedagógico do curso (PPC), a redução de riscos e prejuízos educacionais e a prevenção de dificuldades no futuro. Esse aspecto da realidade não representa obstáculo para muitos docentes e estudantes que na UERN, no Brasil e pelo mundo afora disseminam uma cultura de integralidade e abraçam iniciativas inovadoras.

Maiores benefícios poderão ser alcançados a partir da implementação de um conjunto de políticas e estratégias de inclusão digital que contemplem as peculiaridades e as diversidades que caracterizam os diferentes cenários brasileiros, permitindo reduzir as assimetrias entre eles.

É importante que as escolas médicas e seus integrantes participem das discussões sobre o uso de tecnologias digitais no processo de ensino-aprendizagem e de construção das competências desejadas, bem como na atenção à saúde, de modo a ampliar e levar, para o campo da educação médica, o debate das questões éticas, epistemológicas e tecnológicas que estão sendo repercutidas mundialmente. É necessário buscar respostas aos questionamentos vigentes, construir novos saberes e desenvolver novas práticas, com segurança, primando pela salvaguarda dos direitos de todos.

Para finalizar, ressalta-se um aspecto que, durante a pandemia da síndrome respiratória aguda grave do coronavírus 2 (severe acute respiratory syndrome coronavirus 2 - Sars-CoV-2), ficou bastante evidente: as inter-relações entre a saúde e as demais dimensões humanas, como a economia, o ambiente e a cultura, são muito estreitas. Diante disso, considera-se a interdisciplinaridade como elemento fundamental na formação de profissionais de saúde, pois diversos problemas de saúde têm suas origens em dimensões além da saúde, podendo causar prejuízos incalculáveis e milhões de mortes. Nessa perspectiva, considerar os desequilíbrios nas demais dimensões humanas podem ter desdobramentos na dimensão da saúde. Ademais, assumir o compromisso com a implementação de mudanças poderá resultar em transformações na saúde e na vida de pessoas e comunidades, através de um caminho que pode não existir fora de nós, mas que somos nós mesmos, em nosso interior, e através das pontes que nos interligam com o outro e o mundo.

\section{CONTRIBUICุÃO DOS AUTORES}

Como se trata de uma construção coletiva, todos os autores participaram igualmente de todas as etapas do trabalho.

\section{CONFLITO DE INTERESSES}

Os autores declaram não haver conflito de interesses neste relato.

\section{REFERÊNCIAS}

1. Fundação Universidade do Estado do Rio Grande do Norte. Gabinete do Presidente. Portaria $n^{\circ}$ 346/2020-GP/FUERN, de 15 de março de 2020. Estabelece, no âmbito da FUERN, orientações acadêmicas e administrativas quanto às medidas de proteção e prevenção para o enfrentamento da pandemia decorrente do coronavírus (COVID-19). [acesso 10 ago 2020] Disponível em: http://portal.uern.br/wp-content/ uploads/2020/03/Portaria-346-2020-GPFUERN.pdf. 
2. Universidade do Estado do Rio Grande do Norte. Diretoria de Ensino à Distância. Perfil digital dos alunos da UERN; 2020. [acesso em 10 ago 2020] Disponível em: http://portal.uern.br/wp-content/uploads/2020/04/ Gr\%C3\%A1ficos-Perfil-digital-dos-alunos-da-UERN-reduced.pdf.

3. Governo do Estado do Rio Grande do Norte. Decreto n 29.591 , de 6 de abril de 2020. Dispõe sobre a autorização para certificação de conclusão de cursos de Enfermagem e Medicina, ofertados aos acadêmicos concluintes da Universidade do Estado do Rio Grande do Norte (UERN) do ano letivo atingido pela situação de emergência de saúde pública de que trata a Lei Federal $n^{\circ}$ 13.979, de 6 de fevereiro de 2020, e dá outras providências. Diário Oficial do Estado do Rio Grande do Norte; 6 abr 2020. [acesso em 10 ago 2020] Disponível: http://diariooficial.rn.gov. br/dei/dorn3/docview.aspx?id_jor=00000001\&data $=20200407 \&$ id_ doc $=679365$.

4. Federação Brasileira das Associações de Ginecologia e Obstetrícia. Recomendações FEBRASGO para o GO em tempos de COVID-19. Febrasgo; 2020 [acesso em 5 ago 2020]. Disponível em: https://www. febrasgo.org.br/es/covid19/item/975-recomendacoes-febrasgo-para-ogo-em-tempos-de-covid-19.

5. Fundação Universidade do Estado do Rio Grande do Norte. Portaria $n^{\circ}$ 516/2020-GP/FUERN de 29 de maio de 2020. Reconstitui Comissão Especial de Consulta - CEC para auxiliar o(a) Presidente da FUERN e o(a) Reitor(a) da UERN nas decisões para a retomada das atividades administrativas e acadêmicas ao término do isolamento social. Jornal Oficial da FUERN; 5 jun 2020. [acesso em 11 ago 2020] Disponível em: http://portal.uern.br/jouern/wp-content/uploads/sites/18/2020/06/ UERN_Jornal-Oficial-035-A-05-jun-20.pdf.

6. Universidade do Estado do Rio Grande do Norte. Pró-Reitoria de Gestão de Pessoas. Capacitação e treinamento [acesso em 5 jun 2020]. Disponível em: http://progep.uern.br/default.asp?item=capacitacao\%20 e\%2otreinamento.

7. Cardoso Filho FAB, Magalhães JF, Silva KML, Pereira ISSD. Perfil do estudante de Medicina da Universidade do Estado do Rio Grande do Norte (UERN), 2013. RevBras EducMed. 2015;39(1):32-40 [acesso em 10 ago 2020]. Disponível em: https://www.scielo.br/scielo.php?script=sci_ arttext\&pid=S0100-55022015000100032\&lng=pt\&tlng=pt.

8. Governo do Estado do Rio Grande do Norte. Lei $n^{\circ} 10.480$, de 30 de janeiro de 2019. Dispõe sobre a instituição de cotas e sobre o argumento de inclusão regional nos processos seletivos de vagas iniciais da Universidade do Estado do Rio Grande do Norte - UERN, para alunos egressos da Rede Pública de Ensino, revoga a Lei $n^{\circ}$ 8.258/2002 e a Lei $n^{\circ}$ 9.696/2013, fixando outras providências. Diário Oficial do Estado do Rio Grande do Norte; 30 jan 2019. [acesso em 11 ago 2020] Disponível em: http://diariooficial.rn.gov.br/dei/dorn3/docview.aspx?id jor $=00000001 \&$ data $=20190131$ \&id_doc $=634831$.

9. Fundação Universidade do Estado do Rio Grande do Norte (FUERN). Portaria n'627/2020 - GP/FUERN de 15 de julho de 2020. Determina os valores do auxílio inclusão digital. Jornal Oficial da FUERN; 17 jul 2020. [acesso em 11 ago 2020] Disponível em: http://portal.uern.br/jouern/wpcontent/uploads/sites/18/2020/07/UERN_Jornal-Oficial-039-17-jul-20.pdf.

10. Governo do Estado do Rio Grande do Norte. Informe epidemiológico Coronavirus (COVID-19) atualizado em 6 de agosto de 2020. [acesso em 11 ago 2020] Disponível em: https://portalcovid19.saude.rn.gov.br/wpcontent/uploads/2020/04/132-boletim-covid_06_08_2020-.pdf.

11. ABEM Nacional. Painel "A escola médica na epidemia de COVID-19". Série de 5 vídeos. 2020. [acesso em 11 ago 2020] Disponível em: https://www. youtube.com/playlist?list=PLQq8wWy_jjaPJMHOZ51KywJgLz7YOFsgp.

12. Afya. Ciclo de webinários sobre educação em ciências da saúde. Série de 20 vídeos. 2020. [acesso em 11 ago 2020] Disponível em: https://www. youtube.com/channel/UCdSmo8ileKtHLbyWRm82tHQ/playlists.

13. Xavier ATO, Giovannini PE, De Carvalho TB, Da Silva VMS, Diógenes ICF. Ciclo de palestras sobre o protocolo de atendimento a mulheres e adolescentes vítimas de violência sexual: qualificação profissional e formação de multiplicadores. Revista Extendere. 2015;3(1):69-78 [acesso em 10 ago 2020]. Disponível em: http://periodicos.uern.br/index.php/ extendere/article/view/1636/887.
14. Diógenes ICF, Giovannini PE, Gomes OGF. Projeto de Implantação de um centro de referência integrado para atendimento a crianças, adolescentes e mulheres em situação de violência sexual. 2018. Procedimento $n^{\circ}$ 31.23.2354.0000065/2018-04. Ministério Público do Estado do Rio Grande do Norte.

15. Dantas FCPA. O fluxo de pré-natal na adolescência: adesão, vantagens e fragilidades, na perspectiva das gestantes [monografia]. Mossoró: Universidade do Estado do Rio Grande do Norte; 2018.

16. Diógenes ICF. Conhecimentos, atitudes e práticas de profissionais da Atenção Primária à Saúde no atendimento a mulheres e adolescentes vítimas de violência sexual [dissertação]. Mossoró: Universidade do Estado do Rio Grande do Norte; 2020.

17. Freire I. Programa de extensão Pró-Mulher orienta sobre a importância do Pré-Natal. Uern; 30 jul 2020 [acesso em 5 ago 2020]. Disponível em: http://portal.uern.br/blog/programa-de-extensao-pro-mulher-orientasobre-a-importancia-do-pre-natal/.

18. Barreto B. Programa de extensão traz orientações para mulher vítima de violência. Uern; 21 maio 2020 [acesso em 5 ago 2020]. Disponível em http://portal.uern.br/blog/programa-de-extensao-traz-orientacoes-paramulher-vitima-de-violencia/.

19. Morais A. FACS elabora cartilha com orientação para gestantes sobre cuidados com o Coronavirus. Uern; 20 abr 2020 [acesso em 5 ago 2020]. Disponível em: http://portal.uern.br/blog/facs-elabora-cartilha-comorientacoes-para-gestantes-sobre-cuidados-com-o-coronavirus/.

20. Freire I. Gestantes são atendidas em ambulatórios da FACS e recebem orientações do programa Pró-Mulher. Uern; 15 jun 2020 [acesso em 5 ago 2020]. Disponível em: http://portal.uern.br/blog/gestantes-sao-atendidasem-ambulatorios-da-facs-e-recebem-orientacoes-do-programa-pro-mulher/.

21. Morais A. FACS desenvolve cartilha com orientações para gestantes adolescentes. Uern; 3 jun 2020 [acesso em 5 ago 2020]. Disponível em: http://portal.uern.br/blog/facs-desenvolve-cartilha-com-orientacoespara-gestantes-adolescentes/.

22. Freire I. Programa de extensão Pró Mulher desenvolve cartilha com orientações sobre HPV. Uern; 2 jul 2020 [acesso em 5 ago 2020]. Disponível em: http://portal.uern.br/blog/programa-de-extensao-promulher-desenvolve-cartilha-com-orientacoes-sobre-hpv/.

23. Leite CRM, desenvolvedor. PreNeonatal: plataforma para auxiliar os profissionais e gestantes no rastreamento, monitoramento e acompanhamento do diabetes gestacional. Versão 1.1.1, atualizada em 30 jan 2020 [acesso em 10 ago 2020]. Disponível em: https://play.google.com/ store/apps/details?id=com.uern.aplicacao.releasepreneonatal\&hl=pt-BR.

24. Gomes DA. Preneonatal+: aplicativo móvel para monitoramento e orientação a gestantes no pré-natal [monografia]. Mossoró: Universidade do Estado do Rio Grande do Norte; 2018.

25. Opas Brasil. Folha informativa-COVID-19 (doença causada pelo novo coronavírus) [acesso em 5 ago 2020. Disponível em: https:/www.paho.org/bra/index. php?option=com_content\&view=article\&id=6101: covid19\&ltemid=875\#infografia.

26. Caponi S. Covid-19 no Brasil: entre o negacionismo e a razão neoliberal. EstudAv. 2020;34(99):209-24 [acesso em 10 ago 2020]. Disponível em: https://www. scielo.br/scielo.php?script=sci_arttext\&pid=S0103-40142020000200209\&lng= pt\&nrm=iso.

27. Machado L. Conselho diretor aprova programa de fomento de assistência estudantil da FUERN. Uern; 20 maio 2020 [acesso em 5 ago 2020]. Disponível em: https://portal.uern.br/blog/conselho-diretoraprova-programa-de-fomento-de-assistencia-estudantil-na-fuern/.

28. Barreto B. UERN faz ação para doação de equipamentos tecnológicos para estudantes. Uern; 20 jul 2020 [acesso em 5 ago 2020]. Disponível em: http://portal.uern.br/blog/uern-faz-acao-para-doacao-de-equipamentostecnologicos-para-estudantes/.

29. De Oliveira MA, Nakano TC. Revisão de pesquisas sobre criatividade e resiliência. Temas Psicol. 2011;19(2):467-70[acesso em 11 ago 2020]. Disponível em: http://pepsic.bvsalud.org/scielo.php?script=sci_arttext\&pid=S1413389X2011000200010\&lng=pt.

30. Rose S. Medical student education in the time of COVID-19. JAMA. 2020;323(21):2131-2 [acesso em 10 ago 2020]. Disponível em: https:// jamanetwork.com/journals/jama/fullarticle/2764138. 
31. Liang ZC, Ooi SBS, Wang W. Pandemics and their impact on medical training: lessons from Singapore. Acad Med 2020;95(9):1359-61. Doi: 10.1097/ACM.0000000000003441.

32. Universidade Federal de Minas Gerais. Mídias sociais são aliadas de pacientes com lúpus durante a quarentena. UFMG; 6 ago 2020 [acesso em 8 ago 2020]. Disponível em: https://www.medicina.ufmg.br/midiassociais-sao-aliadas-de-pacientes-com-lupus-durante-quarentena/.

33. Ceccon RF, Schneider IJC. Tecnologias leves e educação em saúde no enfrentamento à pandemia da COVID-19. SciELO Preprints; 24 abr 2020 [acesso em 10 ago 2020]. Disponível em: https://preprints.scielo.org/ index.php/scielo/preprint/view/136/160.

34. Brasil. Resolução $n^{\circ} 3$ de 20 de junho de 2014. Institui Diretrizes Curriculares Nacionais do Curso de Graduação em Medicina e dá outras providências. Diário Oficial da União; 23 ju 2014; Seção 1, p. 8-11 [acesso em 7 ago 2020]. Disponível em: https://pesquisa.in.gov.br/imprensa/jsp/ visualiza/index.jsp?jornal=1\&pagina $=8 \&$ data $=23 / 06 / 2014$.
35. UNESCO IBC-COMEST. Declaração sobre a COVID-19: considerações éticas sob a perspectiva global. UNESDOC; abr 2020 [acesso em 8 ago 2020]. Disponível em: https://unesdoc.unesco.org/ark:/48223/ pfooo0373115_por.

36. Ganascia J.-G. Artificial intelligence: between myth and reality. The Unesco Courier. 2018; 3:7-9 [acesso em 7 ago 2020]. Disponível em: https://unesdoc.unesco.org/ark:/48223/pfooo0265238_por.

37. Dravet F, Castro G. Aprendizagem, meios digitais e afeto: propostas para um novo paradigma na educação superior. Interface (Botucatu). 2019;23: e180321 [acesso em 8 ago 2020]. Disponível em: http://www.scielo.br/ scielo.php?script=sci_arttext\&pid=S1414-32832019000100253\&lng=pt. 